7. Funding and sessional commitment to training will need to be supported at local level. This is not the responsibility of the Royal College of Psychiatrists.
Revised and Approved by the

Court of Electors

27 February 1996

\title{
Letter to the Secretary of State
}

The President sent this letter to the Secretary of State during the Winter Meeting of the College in January 1996. Since then we have been encouraged by the Secretary of State's speech to the House of Commons on 20 February, 1996 which addressed some of these issues.

Dear Mr Dorrell: Concern in the Royal College of Psychiatrists with regard to the implementation of Care in the Community has reached unprecedented levels.

You will be aware that the College has consistently supported the Policy, but has regularly communicated concerns to officials and ministers in recent years. For example I wrote to your predecessor two years ago suggesting that no further in-patient psychiatric beds should be closed until additional community facilities were in place.

The problems that there are in delivering a safe psychiatric service in many parts of the country are well known to you, and also that we are far from being able to provide a service of any quality in most places.

As you consider the responses of Commissioners to Mr Malone's letter to them of last August asking about their progress in meeting the ministerial priority for the service, I thought that I should let you know that I am facing mounting pressure to put a very critical motion of the lack of improvement which has been achieved to the College's annual meeting in July which would inevitably become public.

I think it would be more constructive and in the interest of patients if we could collaborate even more actively with your officials during the next few months to try and produce solutions to some of the problems. In our view one of the continuing impediments to change is the apparent lack of knowledge of a number of Chief Executives of the different elements required for a safe and comprehensive psychiatric service.

We are already working together on the serious deficiencies in psychiatric staffing and on defining the 'seriously mentally ill' and have recently reached agreement on improving the training of those doctors who admit patients to hospital under the Mental Health Act.

I look forward to hearing from you in the near future. Perhaps we could have a meeting to discuss the situation.

Fiona CaLdicott

\section{Psychiatric reports for the Parole Board}

\section{Introduction from the President}

Dr John Reed from the Department of Health wrote to the President in July 1995 following a meeting he had had with the Parole Board. The Parole Board has expressed concern to Dr Reed about the quality and usefulness of some of the reports that they receive written by psychiatrists.
The Courts, from time to time, have expressed a similar concern. It is important to note, of course, that reports for Parole Boards are not the same as reports for the Courts, although both will include mental state at the time of offence. The College has received comments that instructions received from the Parole Boards are often not very clear and we shall be relaying these criticisms to the Parole Board. It must be said, however, that the 
ultimate responsibility for these reports does lie with the general consultant.

The Parole Board has produced the following guidelines for the production of psychiatric reports. These have been endorsed by the Executive and Finance Committee following careful consideration by the Executive Committees for the Forensic and General Psychiatry Sections. A large number of reports are, however, written by general psychiatrists and some by child and adolescent psychiatrists and therefore it has been agreed that these guidelines should be widely disseminated.

The College will ensure that appropriate training for junior psychiatrists and continuing professional development for senior psychiatrists is arranged. We shall also ask the Director of our Research Unit to consider monitoring the standard of reports for both the Parole Board and for the Courts through the Audit Convenors network.

Fiona CaldicotT

President

\section{Parole Board guidelines}

When writing a psychiatric report, you are making an important contribution to the Parole Board's understanding of a prisoner's suitability for early release on licence from custody. The Board, which is made up of judges, psychiatrists, probation officers and independents, sits on panels of three or four members to consider each prisoner in terms of risk to the public (will he or she reoffend while on parole?) and rehabilitation (would a period of supervision in the community - often with conditions to address offending behaviour, live where directed and attend a specific hostel/programme/hospital - reduce the risk of further offending?). The parole dossier from which these judgements are made is available to you from the prison Parole Clerk, and we strongly urge you to look at it. Besides providing useful reports on the prisoner, it will acquaint you with the information which the Board will consider and enable you to avoid needlessly repeating it in your own submission.

In reading through the dossier, interviewing the prisoner, and writing your report, please answer the following questions:

(1) Briefly, what is the prisoner's psychiatric history?

(2) Are there specific psychiatric factors associated with the prisoner's index offence?
(3) Has he/she had any psychiatric treatment in prison during this sentence or previous periods in custody?

(4) Can you trace any change in the prisoner's mental health during this sentence? If so, what has led to it?

To assist the Board in assessing risk and framing any necessary licence conditions, please answer the following questions:

(1) If the inmate is demonstrating bizarre behaviour or disturbance of mood, cognition or belief - and if they believe this to be the consequence of functional or organic psychiatric disorder - is there any prerelease treatment you can recommend and arrange? Does he/she have severe learning difficulties? If the inmate's condition is untreatable, does it preclude parole by elevating the risk of reoffending?

(2) Can the inmate's mental disorder be treated post-release by drugs or cognitive, behavioural or somé other form of therapy? Can you recommend a specific psychiatrist, hospital or out-patient clinic to take on clinical responsibility for the prisoner upon release? If so, the assessment by the National Health Service consultant psychiatrist who will be the responsible medical officer, or his or her deputy, must be completed and oversight agreed prior to the meeting of the Panel. The relevant psychiatrist must provide the Parole Board with written confirmation that he or she is prepared to take on this responsibility. This will help prevent: 1) the psychiatric services being expected to assume responsibility for inapproprlate cases; 2) unacceptable delay between the date of release on parole and the start of psychiatric treatment.

(3) Does the inmate display an attitude either towards his offence, his history of offending or therapeutic programmes which indicates probable lack of cooperation with supervising officers during a licence period? (Even if his problem is treatable, he will not benefit from parole if he is hostlle to examining his offending behaviour or submitting to treatment).

In short, the Board would like your advice on whether or not you consider there are any psychiatric features and related risk issues pertinent to release into the community and whether any extra provisions should be made for his/her rehabilitation. 